Full Paper

\title{
Volatile Organic Compounds in apples: from biosynthesis to compound identification
}

Flüchtige organische Verbindungen im Apfel: von der Biosynthese bis zur deren Identifizierung

Composti Organici Volatili nelle mele: dalla biosintesi all'identificazione dei composti

Lucrezia Angeli ${ }^{1}$, Peter Robatscher ${ }^{1}$, Giulia Chitarrini ${ }^{1}$

${ }^{1}$ Laimburg Research Centre, Vadena, Italy

\section{ABSTRACT}

Apple is one of the mostwidely consumed fruit and its popularity is due to the complex aroma and flavour composition. The aim of this paper is to highlight the role of volatile organic compounds (VOCs) in apples, summarizing their biosynthetic processes, and exploring the analytical methods commonly used for their analysis. This approach could lead to a deeper understanding of the different outputs derived from each technique.

\section{KEYWORDS}

Flavour, sensory active apple compounds, ester, aldehydes, gaschromatography, mass spectrometry

\section{CITE ARTICLE AS}

Angeli Lucrezia, Robatscher Peter Chitarrini Giulia et.al. (2021). Volatile Organic Compounds in apples: from biosynthesis to compound identification. Laimburg Journal 03/2021 DOI: $10.23796 / \mathrm{LJ} / 2021.002$

\section{CORRESPONDING AUTHOR}

Lucrezia Angeli

via della provvidenza, 18 Arco angeli.lucrezia1@gmail.com $+393312576520$ 


\section{APPLE VOLATILES}

The apple is one of the most important fruits, especially in South-Tyrol, where it represents $50 \%$ of Italian production [1]. The apple (Malus domestica) is a fruit of the domesticated tree belonging to the Rosacea family. It is considered a fleshy false fruit, as the ripened ovary and surrounding tissue both become fleshy and edible [2].

An apple provides an energy supply of 50-60 $\mathrm{kcal} / 100 \mathrm{~g}$ and it is made of $80-88 \%$ of water, $0.19 \%$ proteins, $0.36 \%$ lipids, $9-12 \%$ carbohydrates, $0.77 \%$ fibres and $0.26 \%$ minerals [2] [3]. The unripe fruit contains $3-4 \%$ amide, which is converted into sugars during the ripening process. Ethylene plays an important role in this process: it stimulates the ripening of the appleand the variation in acid, sugar, and aroma content. Apple quality depends not only on appearance, firmness, and flavour, but also on sensory attributes. Flavour is one of the most distinctive features of apples and it is determined by both taste and aroma, giving to the fruit a complex combination of sensory effects. The major characteristics contributing to apple aroma are volatile organic compounds (VOCs), since they interact with odour receptors in the nose. Taste is more represented by sugars and organic acids like malic acid and ascorbic acid and is perceived by tongue receptors [3].

\section{VOC BIOSYNTHESIS}

Volatile organic compounds (VOCs) are gaseous aromatic chemicals with a low boiling point; at a temperature of $20{ }^{\circ} \mathrm{C}$, their vapour pressure is higher than $0.01 \mathrm{kPa}$ [4]. Flavour is complex to analyse and over 350 volatile compounds have been detected in the apple. The most abundant VOCs are aldehydes, alcohols, esters, ketones, and ethers deriving from different metabolic pathways [5]. Aldehydes prevail in immature fruits, but their content decreases during the maturation process, while the concentration of alcohols and esters increases. Aldehydes derive from fatty acid catabolism and branched chain amino acids, like L-valine, L-leucine and L-isoleucine, catabolism. Alcohols are assembled thanks to aldehydes reduction, catalysed by the enzyme alcohol dehydrogenase (ADH); they are precursors of esters, that are assembled by the enzyme alcohol acyltransferase (AAT) which transfers an acylic group from acyl-CoA to the hydroxyl group of the alcohol [6].
There are three main pathways responsible for VOCs biosynthesis: lipidic catabolism, protein catabolism, and terpenoids synthesis.

\section{LIPIDIC CATABOLISM: BETA-OXI- DATION AND LIPOXYGENASE}

The lipidic catabolism includes the beta-oxidation of fatty acids and the lipoxygenase (LOX) pathway. Linear chain aldehydes and alcohols are assembled through the betaoxidation, linear chain esters instead through the LOX pathway [7]. The beta-oxidation involves four main reactions that take place in the peroxisome of the cell (fig. 1). To allow the transport across the membrane, the fatty acid is activated by the enzyme acyl-CoA Synthetase to obtain acylCoA [8]. The final products are acetyl-CoA, if the initial fatty acid had equal number of carbons, or propionyl-CoA, if it had odd number of carbons [5].

The LOX pathway is activated during the maturation process of the fruit: the breakdown of chloroplasts leads to the release of fatty acids and so to the increase of membrane permeability. LOX is a dioxygenase that catalyses the oxidation of polyunsaturated fatty acids containing the cis-1.4-pentadien portion and the final products are diene-conjugated hydroperoxydes (HPO). These products can be converted into different compounds through at least six pathways. The most common pathway involves hydroperoxide lyase enzyme (HPL), which transforms HPO in short-chain aldehydes (6$9 \mathrm{C})$. These aldehydes are frequently converted in alcohols thanks to ADH. Alcohols become the substratum of AAT that forms esters (fig. 2) [5].

\section{PROTEIN CATABOLISM}

Branched chain aldehydes, alcohols, and esters are synthetized in the protein catabolism by L-valine, L-leucine and L-isoleucine. The branched chain amino acids are produced inside chloroplasts. It is thought that L-leucine's degradation takes place in mitochondria, whilst degradation of L-valine and L-isoleucine takes place both in mitochondria and peroxisomes. VOCs biosynthesis starts with the transamination of these amino acids, and the resulting products are the respective alfa-ketoacids and the amino group is transferred on the 2-oxo-ketoglutarate [9]. The 2-oxo-acids can be converted into branched chain aldehydes with an oxidative decarboxylation reaction. Then a reduction occurs to transform the aldehydes in alcohols. The 2-oxo-acids can also be converted in branched chain fatty acids and then transformed into alcohols and esters through the reduction of aldehydes reaction (fig. 3) [5].

\section{TERPENOIDS SYNTHESIS: MEVALO- NATE PATHWAY AND METHYL- \\ ERYTRITOL PHOSPHATE PATHWAY}

Terpenoids are produced by two different pathways: the mevalonate (MVA) pathway, which takes place in cytosol, and the methylerythritol phosphate (MEP) pathway, which takes place in chloroplasts [10]. Both pathways result in the formation of isopentyl diphosphate (IPP) and its isomer dimethylallyl diphosphate (DMADP), intermediaries from which all terpenes are derived (fig. 4) [5].

The MVA pathway leads to the formation of sesquiterpenes (C15) and triterpenes (C30), MEP pathway leads to the synthesis of monoterpenes (C10), diterpenes (C20), and tetraterpenes (C40). Apples are particularly rich in monoterpenes and sesquiterpenes [5].

\section{ANALYSIS OF VOCS}

Gas chromatography (GC) is the most used technique for the analysis of VOCs in apples. GC is a chromatographic method that separates different molecules in accordance with their volatility and their affinity with the stationary phase. Compounds elute at different times, ensuring separation [11]. GC is eligible suitable method to perform the separation of VOCs and then to determine them. Molecules, indeed, should have particular characteristics to be analysed efficiently with GC: they need to be volatile and thermally stable. Volatility depends on the vapour pressure and boiling point of the molecules. Thermostability is necessary as GC is carried out at temperatures above room temperature $\left(50-300{ }^{\circ} \mathrm{C}\right)$ and analytes can deteriorate, making their detection difficult. A schematic illustration of the parts composing a GC system is presented below in figure 5 [12]

\section{SAMPLE PREPARATION}

A food product itself cannot generally be directly injected into a $\mathrm{GC}$ instrument without sample preparation. The degradation of non-volatile chemicals due to high temperature can generate a number of undesired peaks and then interfere with the peaks of 
the analytes of interest. It is recommended to extract the constituents of interest from the matrix to reach concentrations that can be detected by the instrument [13] and to remove the other molecules that are not wanted. Some techniques useful to purify the sample are solid phase extraction (SPE), liquid liquid extraction (LLE), solid liquid extraction (SLE) or solid phase micro-extraction (SPME). Sample preparation is an important step to guarantee the quality of the method and a good throughput, although some limitations can occur (tab. 1). For example, it can be expensive, time consuming and some analytes could be not properly extracted [14].

\section{SAMPLE PREPARATION FOR LIQUID INJECTION}

One method to concentrate volatiles is distillation, frequently used is steam distillation at atmospheric pressure or in a vacuum. This technique is efficient, but solvent extraction is needed [12]. It was used to extract apple volatiles in the past; nowadays, other methods are preferred. The most commonly used distillation method nowadays is simultaneous distillation and extraction (SDE). This method is quicker than normal distillation and less solvent is used. However, high temperature could promote lipid oxidation, Maillard browning, and other reactions which introduce errors [14].

Solvent extraction, or liquid-liquid extraction (LLE), is usually the preferred method for the recovery of volatiles from food, but other techniques are more frequently used for apple VOCs recovery. The solvent choice is essentialbecause it directly affects the extraction efficiency. It can be carried out manually with separatory funnels or with automated extractors. Factors affecting liquid-liquid extraction recovery are agitation, salting-out, $\mathrm{pH}$ adjustment, extraction time, and temperature [14]. The main disadvantage of this technique is a possible interference of non-volatile compounds during the analysis [15].

Solid phase extraction (SPE) is a technique that works with a liquid sample phase and a solid extracting phase. It is performed by passing the liquid phase through a column filled with chromatographic packing or a filter disk, and analytes showing affinity with the stationary phase will be collected on it. The phase is next rinsed with water and with a solvent in which analytes of interest are soluble. The advantages of this method compared to liquid-liquid extractions are less solvent required, speed, better precision and accuracy, minimum solvent evaporation, readily automated [14].

Also stir bar sorption extraction (SBSE) is an efficient method for VOCs extraction. A magnet stir bar is coated with sorbent material, placed into the sample and stirred to absorb the analytes. Then and the thermally desorbed analytes enter the gas chromatograph. SBSE has more sensitivity than solid phase micro-extraction (SPME, see next section) due to the higher volume of absorbent phase, which implies less competition and saturation effects. This increases the detection level, but it is not selective for polar compounds [14].

It is theoretically possible to analyse compounds from liquid food and beverages by direct injection of few $\mu$ l (usually $1 \mu \mathrm{l}$ in capillary columns) of sample in a gas chromatograph with a syringe, manually or automated but with possible side effects: thermal degradation of non-volatile chemicals in the injector, decreased separation efficiency due to water in the sample, and contamination of the column with non-volatile materials. However, no solvent is required, it is not expensive, and it can be used for quantitative analyses [16].

\section{SAMPLE PREPARATION FOR HEAD- SPACE ANALYSIS}

In the headspace method, VOCs trapped in the solid or liquid phase of the sample, through vial shaking and regulated temperature, tend to distribute between the vapour phase and the food matrix to reach an equilibrium. The headspace of the sample is collected by a gas-tight syringe and directly injected into the system (direct-headspace) or by a fibre to perform solid-phase microextraction (HS-SPME) [18].

The vapour is then collected and analysed, reducing the introduction of non-volatile compounds in the gas chromatograph. The headspace sampling can be performed in a static or dynamic method. In static headspace (SHS) sampling, a food sample is placed into a vial and the vial is closed with an inert septum and analysed after the equilibration period.

Solid phase micro-extraction (SPME) is one of the most used sample techniques in VOCs analysis and the main innovation is that no solvent is needed [14]. It employs a coated fused silica fibre that is exposed to the headspace above the sample (fig. 6). After the extraction, the fibre is removed from the sample and pulled into the injection system of the GC instrument where the adsorbed volatiles are thermally desorbed from the fibre. One of the most commonly used fibres for VOCs in apple is non-polar polydimethylsiloxane (PDMS) [19]. The advantages of this technique are no solvent contaminations, simplicity, and high precision, thanks to the autosampler that often is utilised [20] These represent the main reasons why HSSPME is commonly used for VOCs sampling in food analysis [21]. On the other hand, the fibre can be easily saturated so that not al volatiles can be extracted causing competitive adsorption [22]. At this purpose, there are different types of material that can be chosen: carboxen/polydimethylsiloxane for gases and volatiles, divinylbenzene for nitroaromatic compounds, polyacrylate for polar semi-volatiles, and carobwax (PEG) for polar compounds and alcohols.

Solid phase dynamic extraction (SPDE) is similar to SPME, but the phase is coated inside a special syringe that draws the headspace of the sample and VOCs are absorbed by the phase [23]. This technique solves the problems related to saturation and competitive absorption [12].

The main advantages of SHS sampling are the minimum level of interferences by nonvolatile chemicals and the efficiency for lowboiling point compounds [24]. The major disadvantage is the low sensitivity of the method for traces analysis. In dynamic headspace (DHS) sampling, or purge-and-trap, the sample is purged with an inert gas that bubbles into the sample, thus facilitating the distribution of the VOCs in the vapour phase [25]. Two needles are inserted in the vial through the seal: one for the carrier gas and one to provide an exit. In the outlet path, a trap is located, which could be a cryogenic trap or an adsorbent trap [26].

Sample preparation in headspace analyses requires the addition of MilliQ water to the lyophilised, pureed, or fresh milled pulp; sodium chloride, which helps the volatilization of the compounds; the use of an internal standard can be used to verify the quality of the extraction or analysis and to obtain semi-quantitative data [25] [27] [28]. A comparison between purge-and-trap method and static headspace is illustrated in figure 


\section{INJECTORS FOR GC}

After the sample preparation and the pretreatments to enhance the quality of the analysis, the sample is ready to be introduced into the gas chromatograph (tab. 2). Both liquid and headspace samples are introduced into the column through two main type of injectors: split/splitless (S/SL) injectors (fig. 8) and programmed temperature vapourisers (PTV) [12] [29].

The S/SL injector can work in the split or the splitless mode. In the split mode, which is the oldest and simplest technique to use, only a fraction of the sample is effectively introduced into the GC system through a glass liner. The rest of the vapourised sample and a huge quantity of carrier gas are eliminated through a split or purge valve. The sample is introduced by a syringe if liquid, or by headspace, if gaseous [11]. The small sample amount, the speed of the flow of the gas, the temperature, the characteristics of the column contribute to the high-resolution separations of the analytes. Other advantages of this technique are that the sample does not need to be diluted and "dirty" samples can be injected by putting a plug of deactivated glass wool in the inlet liner to trap non-volatile compounds. The primary disadvantage is that trace analysis is compromised due to the low amount of sample that enters the column. Another disadvantage is that the splitting process sometimes discriminates the molecules in relation to molecular weight, so that the sample entering the column is not representative of the sample injected [17].

The splitless mode is more sensitive than the split mode and the only difference between them is that the split valve is initially closed. The sample is introduced into the heated injection port. After few minutes, the split valve is opened, and residual vapours carried out of the system. After some time also the analytes are vapourised and carried through the column. Although splitless injection has higher sensitivity than the split technique, it is slow, and it requires both sample dilution and temperature optimisation [14].

Programmed temperature volatizer (PTV) is an injection port in which the sample is introduced at ambient temperature; after the syringe is removed, the temperature is programmed to reach determined values sending the sample into the column. In this system, if the sample is too concentrated, a vent valve is opened so that the sample does not saturate the detector. This technique is useful for large amount of sample injection when it is used in combinations with a split/splitless mode and when thermolabile analytes are expected. It can work both in the split or the splitless mode, but also in the on-column mode and the cold on-column mode. In the on-column method, the needle of the syringe reaches the top of the packing of the column so that most of the sample goes into the stationary phase. The sample is introduced directly into the column, whose temperature is the same as the oven. The initial temperature should be below the boiling point of the solvent [12].

\section{GC COLUMNS}

There are two main types of column in GC: packed columns and capillary columns. Packed columns are filled with small particles with adsorbent properties or coated with the stationary phase. They are metallic or glass tubes of 1-2 $\mathrm{m}$ length and of few $\mathrm{mm}$ diameter. They are employed when the sample quantity is high, as their surface allows a huge amount of sample to be adsorbed. The main disadvantages are that they are less efficient than capillary columns, which are made of a long-fused silica tube of 10-100 m length and of 0.1-0.75 mm diameter in which the stationary phase is layered inside. Lowering the diameter dimension increases efficiency and resolution, but surface area decreases, so only small amounts of sample can be analysed [11].

There are different types of stationary phase that could be employed in GC. Solid adsorbent materials are used both for support and for analyte retention, which is related to their adsorbent capability on the support surface. In gas-liquid chromatography, the liquid stationary phase is layered on the support material. The most commonly used is a polysiloxane with lateral groups that influence polarity and so specificity. Due to the tendency of these groups to become detached from the column, bond phases are often employed [12].

\section{CHROMATOGRAPHIC SEPARATION}

Once analytes enter the column, they are separated thanks to their affinity for the stationary phase. The column is located in an oven that permits the temperature maintenance. The temperature could be held constant during the entire analysis period (isothermal) or it can be modified to increase the peak resolution, resulting in a tempe- rature ramp. For apple analysis, a temperature ramp is preferred, as the matrix is complex [14].

The use of an inert carrier gas permits the achievement of high levels of efficiency and high narrow peaks, so that a high number of chemicals can be separated and detected with only one chromatographic run. The movement of the analytes inside the column by diffusion leads to less dispersion of the chromatographic bands. The commonly used gases are argon, helium, hydrogen, and nitrogen, which are relatively cheap, readily available, inert, and safe, except for hydrogen, which is explosive [11].

The capability of separating compounds depends on retention and column efficiency. Retention is affected by the time spent in the mobile phase rather than in the stationary phase, by the volatility, column temperature, and by the interaction with the stationary phase. The low density of the carrier gas facilitates elution, allowing few interactions with the coating. A reduction in the column temperature could result in a prolongation of retention time due to the decrease in volatility [12].

\section{DETECTORS USED IN GC}

Once compounds are separated and exit the chromatographic column, a detector is employed to permit identification and quantification.

There are different types of detectors that can be coupled with GC and perform in an efficient manner; the most used are the flame ionisation detector (GC-FID), mass spectrometry (GC-MS), and olfactometry (GC-O). Quite common are also the thermal conductivity detector (TCD), electron capture detector (ECD), flame photometric detector (FPD), photoionisation detector (PID), and Fourier transform infrared spectroscopy (FT-IR). They all have different characteristics and can either be used for qualitative analysis and quantitative analysis (tab. 3).

\section{FLAME IONIZATION DETECTOR}

The FID is the most commonly used GC detector, and it features a small oxy-hydrogen flame that burns compounds eluting from the column. It is an example of an ionization detector created specifically for GC. During the process, a potential (generally $300 \mathrm{~V}$ ) is applied across the flame, so that ions are produced and collected, forming a current that becomes the signal. The current is 
proportional to the organic ions present in the flame and it is amplified by a high impedance circuit and recorded [12]. As water is produced during the combustion process, the detector must be heated to at least $125{ }^{\circ} \mathrm{C}$ to avoid water condensation, although it is usually set at $250{ }^{\circ} \mathrm{C}$. Although the operating mechanism is not fully understood, FID responds to all organic compounds that are burnt in the hydrogen flame and the signal is proportional to the carbon content. Thus, all hydrocarbons should show the same response, per carbon atom. When heteroatoms like nitrogen or oxygen are present, the factor decreases. The response factors are necessary for good quantitative analysis, so gases must be pure and free of organic interferences that would increase the background ionisation. Inorganic compounds that do not contain carbons do not burn and are not detected [14]. Thus, it is possible to analyse samples containing water, since it does not interfere with the detection, which is a huge advantage. FID is a universal, mass flow rate technique that directly measures the amount of analyte irrespective of the volume of the carrier gas. Operation at constant flow may be necessary for quantitative analysis in GC, as flow rates will change if the $\mathrm{GC}$ is being run at a constant pressure during programmed temperature performances. This is possible thanks to the employment of electronic flow controllers and in this way peaks areas are unaffected. Its advantages are a good sensitivity, a large linearity, simplicity, robustness, and adaptability to all sizes of columns. The main disadvantages are that FID is low selective and it is destructive, so it cannot be coupled with other detection systems [30]. However, it is possible to split the flow so that a portion of it is conducted to the FID and the other portion to a non-destructive detector, e.g., olfactometry [31]. An illustration of FID is presented in figure 9 .

\section{MASS-SPECTROMETRY}

Mass-spectrometry has become over the past few decades one of the most important techniques for the detection of compounds, as it can be coupled to chromatography systems (both GC and liquid chromatography) and it is efficient both for qualitative and quantitative analyses. Today GC-MS systems are an essential part of most analytical laboratories. The basic principle of mass spectrometry is the ability to place a charge on a molecule generating ions during a process called ionisation. These ions are then detected in relation to their mass-to-charge ratio $(\mathrm{m} / \mathrm{z})$ thanks to the mass analysers and determined qualitatively or quantitatively by their respective $\mathrm{m} / \mathrm{z}$ abundance in highsensitivity detectors. The resulting signals on the data system (computer) are mass spectra that reveal the fragmentation leading to identification and quantification of the compound of interest [32]. Each mass spectrum provides mass spectral data of the eluting species. Thus, the components can be identified after separation on the chromatographic system one after the other by their individual mass spectrum. Peak identification is possible thanks to the comparison with libraries. The improved speed, capacity, and flexibility of current GC-MS systems are the main reasons why they have become so common in most analytical laboratories [33]. A mass spectrometer consists of an inlet port, an ion source, a mass analyser, and a detector which are operated under vacuum conditions (fig. 10). Vacuum is produced by pumps and it is necessary for two main reasons: to avoid reactions between the charged ions and other gaseous molecules, and for proper functioning of the ion lenses, mass analyser electrodes, and iondetectors [12]. Vacuum performance is responsible for the sensitivity and the resolution of mass spectrometers.

\section{ION SOURCES}

The most common used ion sources in GCMS are electron impact ionisation (EI) and chemical ionisation $(\mathrm{Cl})$.

The El source permits the ionisation of the molecules accomplished by impact of a highly energetic electron beam. Electrons are drawn out from a tungsten or rhenium filament by a collector energy of $70 \mathrm{eV}$. These high energy electrons excite the neutral compounds causing the loss of an electron and fragmentation, due to the high internal energy. El is a hard ionisation technique and usually produces positive, small ions with a single charge [32]. This ionisation technique is considered more sensitive and robust than others. In particular, electrons emitted from the tungsten filament are accelerated to an anode placed at the opposite side of the filament. In this way, they are able to acquire high energy $(70 \mathrm{eV})$. When electrons hit a molecule, they transfer a part of their energy provoking electron expulsion from the neutral molecule and forming the positive charged molecular ion. All the ions produced are repulsed from a focusing plate to a series of accelerating plates maintained at a growing positive potential. In this way, the ion energy is increased enabling a maximum number of ions reaching the analyser [12].

$\mathrm{Cl}$ is used as a soft ionisation technique in comparison to $\mathrm{El}$, as molecular weight determination is essential for structure elucidation. In this method, a reagent gas $(\mathrm{CH} 4$, $\mathrm{NH} 3$ ) is added to the ion chamber where it is ionised, producing an ion that runs through further reactions to create secondary ions. The secondary ions allow a gentle ionisation of the sample, leading to less fragmentation and more simple mass spectra in comparison with El. Chemical ionisation permits formation of both positive (PICI) and negative (NCl) ions [14].

\section{MASS ANALYZERS}

After ionisation, the ions are repelled and accelerated by lenses into the mass analyser, which represents the heart of a mass spectrometer and where ions are separated by $\mathrm{m} / \mathrm{z}$ ratio by either magnetic or electrical fields. Mass range, accuracy, sensitivity and resolution depend on it. Different analysers are currently used, but the most popular for GC-MS are quadrupole (Q), time of flight (TOF), or tandem mass spectrometry, e.g., triple quadrupole or Q-TOF and a GC coupled to an Orbitrap mass analyser was introduced recently on the market [32].

The quadrupole mass analyser is made of four metal rods that generate two equals but out-of-phase electric potentials: one is alternating current $(A C)$ frequency of applied voltage that falls in a radiofrequency (RF) range and one is direct current (DC). The rods are mounted in a square configuration along the $z$ axis and the pairs of opposite rods are each held at the same potential. The potential difference can be modified to produce an oscillating electrical field between two of the opposite rods, so that they have equal but opposite charge. The ion entering the quadrupole field will be attracted toward a rod at a negative potential, but if the potential change before the ion collides, it will be deflected [12]. Thus, every ion with a stable flight path traces a sine wave-type pattern on its way to the detector. A schematic illustration of a functioning quadrupole is presented in figure 11 . Depending on the combination of radio frequency and potentials, ions in the selected $\mathrm{m} / \mathrm{z}$ range or even only a single ion can have a stable path and reach the detector generating a signal. The unstable ions collide with one of the 
rods and are pumped away by the vacuum pumps. The linear quadrupole can work in full scan analysis or in single ion monitoring (SIM). With the full scan analysis, it is possible to detect all ions in a defined range of $\mathrm{m} / \mathrm{z}$, resulting in a high number of ion acquisitions. However, the resulting chromatogram can contain some ions that interfere with the response. In SIM acquisition, one or more fragments with a characteristic $\mathrm{m} / \mathrm{z}$ can be chosen and detected in order to facilitate the quantification of traces. The advantages of quadrupole are the simplicity of the mechanism, small size, moderate costs, and rapid scanning [17].

The time-of-flight mass analyser separates ions according to the time required from each ion to reach the detector while running at a defined distance. The ions generated by the ionisation source are kicked by a repeller voltage with an equivalent amount of kinetic energy at a specific time, so that all ions have the same kinetic energy. Thus, ions with a smaller $\mathrm{m} / \mathrm{z}$ travel more rapidly and reach the detector earlier than ions with a higher $\mathrm{m} / \mathrm{z}$. The time of flight for each ion is directly correlated with the ion mass. Ions of the same $\mathrm{m} / \mathrm{z}$ value are dishomogeneous with respect to kinetic energy, and consequently speed, and exit time from the source [14]. These aspects reflect in a peak width enlargement and in consequent decrease of mass resolution. To overcome the kinetic energy distribution of ions with the same $\mathrm{m} / \mathrm{z}$ ratio, a reflectron system is employed. It acts as an ion mirror that focuses ions of different kinetic energies in time. By reflectron, both higher resolution and higher peak intensity are obtained, as ion drift path length is increased by bouncing ions in a $\mathrm{V}$ or $\mathrm{W}$ pattern without increasing the instrument footprint [32]. Theoretically, TOF instruments do not have an upper mass range. Indeed, they are suitable for large molecules and biopolymer analysis and have fast acquisition cycles since they transmit in full scan mode. The detector is usually a continuous dynode version of an electron multiplier: ions strike the semi conductive surface and release a cascade of electrons, which are accelerated by a potential difference resulting in signal amplification. The main advantages of TOF instruments are the unlimited $\mathrm{m} / \mathrm{z}$ range, high sensitivity, high acquisition rate, and accurate mass measurement. A schematic illustration of a TOF is presented in figure 12 [12].

To improve sensitivity and quantification accuracy, tandem mass spectrometry consisting of two analysers is usually employed [34]. The two analysers are separated by a collision cell into which an inert gas collides with the ions and determines the secondary fragmentation.

In GC systems, triple quadrupole (QqQ) and Q-TOF are mostly used. In triple quadrupole, three quadrupoles are placed in series and allow selected reaction monitoring (SRM) / multiple reaction monitoring (MRM) acquisition for targeted analyses. In this analyser, the first quadrupole works as mass spectrometer, so it permits transition of selected ions in a mass range or in a specific mass. The second quadrupole (q2) acts as a collision cell, where further fragmentations are created. No fields are applied in q2. The third quadrupole analyses the fragmentation products exiting from q2. The SMR / MRM mode is employed thanks to its sensitivity and selectivity, as it can filter ions of a selected mass. The ions are fragmented in a compound-specific way and resulting fragments are monitored. This selectivity can be further improved using two SRM transition, a qualifier, and a quantifier one, for each analyte [32]. A compound is confirmed when both transitions are found in the sample with the same transition intensity ratio as in the standard. MRM is the application of SMR to multiple product ions from one or more precursor ions, as it scans rapidly over multiple mass windows. The main disadvantage is the low resolution of the triple quadrupole mass spectrometer. In Q-TOF, a quadrupole is combined with a time-offlight analyser, leading to high resolution spectra and high sensitivity [14].

\section{OLFACTOMETRY AND ELECTRONIC NOSE}

In Gas Chromatography-Olfactometry (GC$O)$, human assessors play as a selective and sensitive detector for odour-active compounds, and so VOCs, eluting from a GC, can be detected. The human panelists take the place of more conventional detectors, such as FID, and sniff the compounds arriving at the nose through a designed port [35]. The aim of this method is to determine the odour activity of volatile molecules present in sample extracts [36]. Several factors and properties can play a role in generating an olfactory perception: the odour threshold (OT), the minimum concentration at which $50 \%$ of human assessors can detect the presence of an odour; physical and chemical properties, including: volatility to permeate the air near the sensory area; slight water solubility and lipid solubility to interact with lipid material of nasal cilia; intensity, the strength of the odour above the recognition threshold. Each compound eluted from GC is submitted to trained assessors who describe the odour perceived and quantify the intensity [37]. This technique is usually coupled with a mass spectrometer (GC-O/MS) to enhance compound identification with mass spectral information. In this case, the flow of eluate is split so that the compounds reach both the detectors simultaneously, allowing a comparison between signals. The eluate reaches the odour port through an uncoated transfer line, and it is sniffed into a glass or a PTFE conical port suitable for a nose. The transfer line is heated to prevent the condensation of analytes and humidified air is added to prevent the drying of nasal mucous membranes [38].

GC-O is important since a GC detector is not representative of odour activity: the highest peak in a chromatogram is not necessarily the most important odorant in the sample. There are chemicals with a high odour potency that show low response in MS or FID [39]. However, there are several factors that influence the quality of data collected by GC$O$ : the method used to extract VOCs from the samples, the set-up of GC instrument, the peak shape, and the stationary phase [35].

There are several detection methods developed during the few past decades and the most used are the following three.

The frequency detection method involves a panel of 6-12 people who sniff the same sample to provide the proportion of assessors that perceived the odour analyte at a given retention time. Each aroma can be evaluated through Nasal Impact Frequency (NAF) or Surface of Nasal Impact Frequency (SNIF) values [40]. The main advantage of this technique is its simplicity, repeatability of results and their possible application to a population. On the other hand, there is a limitation in the scale of measurements, as it is assumed that detection frequency correlates with actual odour intensity perceived [37].

The dilution-to-threshold method is useful to provide a quantitative representation of the odour potency of a compound based on the ratio between its concentration in the sample and its sensory threshold in the air [41]. A dilution series of an extract is prepared and then analysed with a GC-O [42]. 
The assessors determine the lowest dilution at which the compound can still be sensed. The most frequently reported dilution methods are AEDA (Aroma Extracted Dilution Analysis) and CharmAnalysis ${ }^{\mathrm{TM}}$ (Combined Hedonic Aroma Response Measurement). This technique has the disadvantage that the intensity of the perceived stimulus is not measured and therefore it is not regarded as a psychophysical measurement [38]

In the direct intensity method, odour intensity and duration are recorded using category scales or unstructured line scales. This technique involves the posterior intensity evaluation method, in which single time-averaged measurements are registered after analyte elution, and OSME (named after the Greek word that means odor, oo $\mu \eta$ ), which is a dynamic measurement where the appearance of an odour, its maximum intensity, and its decline are constantly recorded [43]. A potential disadvantage of direct intensity method is the high level of training assessor require in order to obtain a personal reproducibility.

GC-O is widely used for assessment of apple aroma, usually coupled with mass spectrometry or FID (fig. 13) [44].

Although the GC-O technique permits a qualitative and quantitative evaluation of the odour of each compound, a limitation is the co-elution of different analytes. It provides the opportunity to determine whether a molecule appears in the sample above the threshold of sensory detection, what type of odour it is, and its intensity. Results are often not reliable, due to complexity of food aroma and to human subjective response to odours [38]. Electronic nose (e-nose) is an alternatively method to measure the sensory quality of food: it is an instrument able to mimic the sense of smell and to discriminate among complex odours using an array of chemical sensors. The sensor array generates a so-called "smellprint". Thanks to a database created based on patterns or fingerprints from human odours and trained pattern recognition systems it is possible to classify and identify unknown odours [45].

The detection system of an electronic nose commonly consists of an array of gas sensors, but nowadays also MS is common. The most popular sensors are divided into four main categories: conductive, piezoelectric, electrochemical, and optical sensors. The fifth group of sensors is based on GC/MS. The employment of an e-nose in apple fla- vour analysis is becoming increasingly common to overcome limitations due to olfactometry [46].

\section{QUALITATIVE, SEMI-QUANTITA- TIVE AND QUANTITATIVE ANA- LYSIS}

Quantitative analysis is not always possible with a GC system, but also qualitative analysis is important, especially for untargeted approaches. In qualitative analysis, attention is given to retention parameters, assuming that all method adjustments to improve resolution power and obtain high narrow peaks have been made (good sample preparation, temperature ramp, choice of detector). Retention time (RT) can be used only if column parameters (length, stationary phase and its thickness, temperature, and pressure) are kept constant. Thus, retention time is characteristic of a GC system, but is not unique and if the retention time of an analyte matches the RT of the standard, the identification can be made [12]. However, this procedure is not reliable if the number of analytes is large, or the retention volumes are not specific. The retention in dex (RI) of Kovats has become the most reliable method for qualitative assessment, since it adjusts retention volumes on a homologous series of $n$-alkanes. Three levels of identification are adopted: the first level is the match of the mass spectrum obtained with a similar mass spectrum acquired in the library (e.g., NIST) available with the instrument software or online. The second level consists in comparing the experimental RI with the theoretical RI of the same compound found in the libraries considering the type of column. The third level, which represents the final confirmation, implies the standard injection: if standard RI matches analyte $\mathrm{RI}$, the identification of the compound is confirmed [14].

Quantitative analysis is more sophisticated and needs accurate good sample preparation, instrument and method validation, and quality assurance are necessary. To minimize errors, it is important to gain precision and accuracy, that affect repeatability and reproducibility. The choice of the detector is fundamental in quantitative analysis, and tandem mass spectrometry is preferable rather than FID or linear mass analysers [32]. In particular, triple quadrupole and Q-TOF are commonly employed for VOCs analyses [34], [47]. Quantification is more accurate when the analysis is targeted and SRM or
MRM acquisition is preferred. There are several methods to increase accuracy and precision for a correct measurement and one of them is area normalization. It is employed for semi-quantitative analysis, where quantification is not required but statistical analysis can be done to describe and differentiate samples measured in the same batch. It is useful when it is not necessary to know the exact amount of analyte in the sample, but comparison between analytes is significant. Peak area of the compound of interests should be normalized using the analyte area and internal standard area ratio [12] As mentioned above, internal standard is important to evaluate the quality of the analysis, but also to provide a measure for semi-quantitative analyses. Internal standard can never be naturally present in the matrix and cannot overlap with any sample peaks. It should have chemical properties similar to analytes, but it should be easily detectable and its concentration in the sample should be highly precise. For apple volatile analysis, 2-octanol or 1-heptanol are commonly used [27]. For quantitative analysis, a calibration curve is required. It should include standards at known concentrations, and they should be subjected to the same procedure as the sample. A calibration curve is essential to calculate the exact concentration of a specific analyte in the sample.

Not only is detection method responsible for accuracy of quantitative results, but also sample preparation and injection represent a crucial step. Looking at literature, quantitative analysis for VOCs is often conducted through HS-SPME in splitless mode [20], [25], [26], [48], and usually with more than one detector. Mass spectrometry is widely used, coupled with flame ionisation detector/olfactometry or electronic nose [36] [44] [45] [46]; also, tandem mass spectrometry is frequently employed [34] [47].

\section{CONCLUSION}

The analyses of VOCs in the apple are important to monitore the quality of the fruit, to satisfy the consumers' request for new aromas and to find differences between varieties or growing conditions. Gas Chromatography is a widely used technique that permits the analysis of different compounds. Several methods for sample preparation are used in order to improve the quality of the analysis. They should be carefully chosen for the analysis of VOCs in apples, since they have pros and cons. For example, headspace sampling requires little time for 
sample preparation, while liquid injection is more effective for quantification purposes. For both qualitative and quantitative analyses, the detector is essential, so it should be chosen considering several aspects in order to get accurate information about the samples under investigation. Mass spectrometry gives information about hundreds of molecules, leading to high reliability of results but the instrument requires periodic maintenance. Flame Ionization Detector is less delicate and commonly employed for targeted analyses. In all cases, the technicians should be expert both for problems identifications and data analysis.

\section{ZUSAMMENFASSUNG}

Der Apfel ist eine weit verbreitete Frucht und seine Beliebtheit hängt stark mit dessen aromatischen, häufig komplexen Zusammensetzung zusammen. Der Zweck dieses Artikels ist es, die Rolle der flüchtigen organischen Verbindungen im Apfel hervorzuheben, ihre Biosynthesevorgang zusammenzufassen und die wichtigsten Analysenmethoden, mit denen diese Substanzen gemessen werden, zu beschreiben. Dieser Ansatz erlaubt das bessere Verständnis der Ergebnisse einer jeden Analysentechnik.

\section{RIASSUNTO}

La mela è un frutto ampiamente consumato e la sua popolarità è legata alla complessa composizione aromatica. Lo scopo di questo articolo è quello di evidenziare il ruolo dei composti organici volatili nella mela, riassumendo il loro processo biosintetico e analizzando quali sono $i$ metodi analitici più comunemente utilizzati per la loro analisi. Questo approccio permette di approfondire la conoscenza dei diversi risultati che si possono ottenere da ogni tecnica.

\section{REFERENCES}

[1] Giannetti V., Boccacci Mariani M., Mannino P. et al. (2017). Volatile fraction analysis by HS-SPME/GC-MS and chemometric modeling for traceability of apples cultivated in the Northeast Italy. Food Control 78, 215221, DOI: 10.1016/j.foodcont.2017.02.036.

[2] Campeanu G., Neata G., Darjanschi G. (2009). Chemical Composition of the Fruits of Several Apple Cultivars Growth as Biological Crop. Notulae Botanicae Horti Agrobotanici Cluj-Napoca, 37 (2), 161-164, DOI: $10.15835 /$ nbha3723465.

[3] Dixon J., Hewett E.W. (2000). Factors affecting apple aroma/flavour volatile concentration. A Review. New Zealand Journal of Crop and Horticultural Science 2000, 28 (3), 155173, DOI: 10.1080/01140671.2000.9514136.

[4] Dewful J., van Langenhove H., Wittman G. (2002). Analysis of volatile organic compounds using gas chromatography. Trends in analytical chemistry 21 (9-10), 637-646, DOI: 10.1016/S0165-9936(02)00804-X.

[5] Espino-Díaz M., Sepúlveda D.R., GonzálezAguilar G. et al. (2016). Biochemistry of Apple Aroma: A Review. Food Technology and Biotechnology 54 (4), 375-394. DOI: 10.17113/ftb.54.04.16.4248.

[6] Defilippi B.G., Kader A.A., Dandekar A.M. (2005). Apple aroma: Alcohol acyltransferase, a rate limiting step for ester biosynthesis, is regulated by ethylene. Plant Science 168 (5), 1199-1210,

DOI: 10.1016/i.plantsci.2004.12.018.
[7] Goepfert S., Poirier Y. (2007). Beta-oxidation in fatty acid degradation and beyond. Current opinion in plant biology 10 (3), 245-25 DOI: 10.1016/j.pbi.2007.04.007.

[8] Botany Studies. Fatty acid oxidation. Retrieved July 30, 2020, from http://botanystudies.com/fatty-acid-oxidation/.

[9] Smit B.A., Engels W.J.M., Smit G. (2009). Branched chain aldehydes: production and breakdown pathways and relevance for flavour in foods. Applied microbiology and biotechnology 81, 987-999, DOI: 10.1007/s00253-008-1758-x.

[10] Yang D., Du X., Liang X. et al. (2012). Different Roles of the Mevalonate and Methylerythritol Phosphate Pathways in Cell Growth and Tanshinone Production of Salvia miltiorrhiza Hairy Roots. PLOS ONE 7, e46797, DOI: 10.1371/journal.pone.0046797.

[11] Hage D.S., Carr J.D., Dallanoce C.M.L. et al. (2012). Chimica Analitica e Analisi Quantitativa. Piccin, Padua, Italia, here: p. 543.

[12] McNair H.M., Miller J.M. (2009). Basic Gas Chromatography. John Wiley \& Sons, Hoboken, NJ, USA, here: p. 14.

[13] Zhao Z., Barron A.R. (2015). Dynamic Headspace Gas Chromatography Analysis. In: Barron A.R. (ed.). Physical Methods in Chemistry and Nano Science. Retrieved July 15, 2020 from https://cnx.org/contents/uieDnVBC@20.16:HwglYzq6@2/Dynamic-Headspace-Gas-ChromatographyAnalysis.
[14] Nielsen S.S. (ed.) (2017). Food Analysis. (Food Science Text Series). Springer International Publishing, Cham, Schweiz, here: $p$. 61. DOI: 10.1007/978-3-319-45776-5.

[15] Adorno M.A.T., Hirasawa J.S., Varesche M.B.A. (2014). Development and Validation of Two Methods to Quantify Volatile Acids (C2-C6) by GC/FID: Headspace (Automatic and Manual) and Liquid-Liquid Extraction (LLE). American Journal of Analytical Chemistry 05 (7), 406-414, DOI: 10.4236/ajac.2014.57049.

[16] Villén J., Senorans F.J., Reglero G. et al. (1995). Analysis of Wine Aroma by Direct Injection in Gas Chromatography without Previous Extraction. Journal of Agricultural and Food Chemistry 43 (3), 717-722, DOI: 10.1021/jf00051a029.

[17] Cozzi R., Ruaro T., Protti P. (1994). Analisi chimica: moderni metodi strumentali. Zanichelli, Bologna, Italia, here: p. 769.

[18] Knowler R. (2011). Theory of Headspace Sampling. Owlstone Ltd., Cambridge, United Kingdom, here: p. 1.

[19] Vas G., Vékey K. (2004). Solid-phase microextraction. A powerful sample preparation tool prior to mass spectrometric analysis. Journal of mass spectrometry 39 (3), 233254, DOI: 10.1002/jms.606.

[20] Charry-Parra G., DeJesus-Echevarria M., Perez F.J. (2011). Beer Volatile Analysis. Optimization of HS/SPME Coupled to GC/MS/FID. Journal of Food Science, 76 (2), C205-C211, DOI: 10.1111/j.17503841.2010.01979.x. 
[21] Bojko B., Reyes-Garcés N., Bessonneau V. et al. (2014). Solid-phase microextraction in metabolomics. TrAC Trends in Analytical Chemistry 61, 168-180, DOI: 10.1016/j.trac.2014.07.005.

[22] D'Auria M., Racioppi R., Velluzzi V. (2008). A Comparison of Results Obtained Using Liquid Injection and Headspace Solid-Phase Microextraction for Crude Oil Analysis by GC with Mass Spectrometer Detection. Journal of Chromatographic Science 46 (4), 332-338, DOI: 10.1093/chromsci/46.4.332.

[23] Schmidt K., Podmore I. (2015). Solid Phase Microextraction (Spme) Method Development in Analysis of Volatile Organic Compounds (Vocs) as Potential Biomarkers of Cancer. Journal of Molecular Biomarkers and diagnosis 6:253, DOI: 10.4172/21559929.1000253.

[24] Lourdes Cardeal Z. de, Guimarães E.M., Parreira F.V. (2005). Analysis of volatile compounds in some typical Brazilian fruits and juices by SPME-GC method. Food additives and contaminants $22,508-513$ DOI: $10.1080 / 02652030500132893$.

[25] Song J., Gardner B.D., Holland J.F. et al. (1997). Rapid Analysis of Volatile Flavor Compounds in Apple Fruit Using SPME and GC/Time-of-Flight Mass Spectrometry. Jour nal of Agricultural and Food Chemistry 45 (5), 1801-1807, DOI: 10.1021/jf9608229.

[26] Ruiz-Beviá F., Font A., García A.N. et al. (2002). Quantitative analysis of the volatile aroma components of pepino fruit by purgeand-trap and gas chromatography. Journal of the Science of Food and Agriculture 82 (10), 1182-1188, DOI: 10.1002/jsfa.1169.

[27] Aprea E., Gika H., Carlin S. et al. (2011). Metabolite profiling on apple volatile content based on solid phase microextraction and gas-chromatography time of flight mass spectrometry. Journal of Chromatography A 1218 (28), 4517-4524, DOI: 10.1016/i.chroma.2011.05.019.

[28] Ferreira L., Perestrelo R., Caldeira M. et al. (2009). Characterization of volatile substances in apples from Rosaceae family by headspace solid-phase microextraction followed by GC-qMS. Journal of separation science 32 (11), 1875-1888, DOI: $10.1002 /$ issc. 200900024 .

[29] Split and splitless injectors. Retrieved August 10, 2020, from https://aibolita.com/addiction-treatment/45737-split-and-splitlessinjectors.html.

[30] Lo Scalzo R., Testoni A., Genna A. (2001). 'Annurca' apple fruit, a southern Italy apple cultivar: textural properties and aroma composition. Food chemistry 73 (3), 333-343, DOI: 10.1016/S0308-8146(00)00306-X.
[31] AAVOS International. Flame ionization detector FID. Retrieved August 10, 2020, from https://aavos.eu/glossary/flame-ionizationdetector-fid/.

[32] Gross J.H. (2017³). MassSpectrometry. A Textbook. Springer, Berlin, Heidelberg, Deutschland, here: p. 325

[33] Shimadzu. Introduction to mass analyzers. Retrieved July 23, 2020, from https://www.shimadzu.com/an/lcms/support/fundamental/mass analyzers.html.

[34] Vrhovsek U., Lotti C., Masuero D. et al. (2014). Quantitative metabolic profiling of grape, apple and raspberry volatile compounds (VOCs) using a GC/MS/MS method. Journal of chromatography B 966, 132-139, DOI: 10.1016/j.jchromb.2014.01.009.

[35] Leland J.V., Schieberle P., Buettner A. et al. (eds.) (2001). Gas Chromatography-Olfactometry. (ACS Symposium Series ; 782). American Chemical Society, Washington, DC, here p. 1, DOI: 10.1021/bk-20010782.ch001.

[36] Niu Y., Wang R., Xiao Z. et al. (2019). Characterization of ester odorants of apple juice by gas chromatography-olfactometry, quantitative measurements, odour threshold, aroma intensity and electronic nose. Food Research International 120, 92-101, DOI: 10.1016/j.foodres.2019.01.064.

[37] Delahunty C.M., Eyres G., Dufour J.-P. (2006). Gas chromatography-olfactometry. Journal of separation science 29 (14), 21072125, DOI: $10.1002 /$ jssc. 200500509.

[38] Wardencki W., Chmiel T., Dymerski T. (2013). 7 - Gas chromatography-olfactometry (GC-O), electronic noses (e-noses) and electronic tongues (e-tongues) for in vivo food flavour measurement. In: Kilcast D. (ed.). Instrumental Assessment of Food Sensory Quality. A practical guide. (Woodhead Publishing Series in Food Science, Technology and Nutrition). Woodhead Publishing, Sawston, United Kingdom, pp. 195-229, DOI: $10.1533 / 9780857098856.2 .195$.

[39] Komthong P., Hayakawa S., Katoh T. et al (2006). Determination of potent odorants in apple by headspace gas dilution analysis. LWT - Food Science and Technology 39 (5), 472-478, DOI: 10.1016/j.Iwt.2005.03.003.

[40] Van Ruth S.M. (2001). Methods for gas chromatography-olfactometry. A review. Biomolecular Engineering 17 (4-5), 121-128, DOI: 10.1016/S1389-0344(01)00070-3.

[41] Jackson F.J., Hinsksen H.F. (eds.)(2002) Analysis of taste and aroma. (Molecular Methods of Plant Analysis ; 21). Springer, Berlin, Heidelberg, Deutschland, here: p. 239.
[42] Garruti D.S., Franco M.R.B., da Silva M.A.A.P. et al. (2003). Evaluation of volatile flavour compounds from cashew apple (Anacardium occidentale $\mathrm{L}$ ) juice by the Osme gas chromatography/olfactometry technique. Journal of the Science of Food and Agriculture 83 (14), 1455-1462, DOI: $10.1002 /$ jsfa.1560.

[43] Brattoli M., Cisternino E., Dambruoso P.R. et al. (2013). Gas chromatography analysis with olfactometric detection (GC-O) as a useful methodology for chemical characterization of odorous compounds. Sensors 13 (12), 16759-16800, DOI: $10.3390 /$ s131216759.

[44] Plotto A., McDaniel M.R., Mattheis J.P. (2000). Characterization of Changes in 'Gala' Apple Aroma during Storage Using Osme Analysis, a Gas Chromatography-Olfactometry Technique. Journal of the American Society for Horticultural Science 125 (6), 714722, DOI: 10.21273/JASHS.125.6.714.

[45] Zhu D., Ren X., Wei L. et al. (2020). Collaborative analysis on difference of apple fruits flavour using electronic nose and electronic tongue. Scientia Horticulturae 260, 108879 , DOI: 10.1016/j.scienta.2019.108879.

[46] Wu H., Wang J., Yue T. (2017). Variety-based discrimination of apple juices by an electronic nose and gas chromatography-mass spectrometry. International Journal of Food Science and Technology 52 (11), 2324-2333, DOI: $10.1111 / \mathrm{ijfs} .13514$

[47] Martín-García B., Verardo V., León L. et al. (2019). GC-QTOF-MS as valuable tool to evaluate the influence of cultivar and sample time on olive leaves triterpenic components. Food research international 115, 219 226, DOI: 10.1016/j.foodres.2018.08.085.

[48] Mathure S.V., Wakte K.V., Jawali N. et al. (2011). Quantification of 2-Acetyl-1-pyrroline and Other Rice Aroma Volatiles Among Indian Scented Rice Cultivars by HSSPME/GC-FID. Food Analytical Methods 4, 326-333, DOI: 10.1007/s12161-010-9171-3.

[49] Quadrupole mass analyzer. Retrieved May 14, 2021, from https://commons.wikimedia.org/wiki/File:Quadrupole_mass_analyzer.svg.

[50] Qian Y.L., Zhang D., An Y. et al. (2021). Characterization of Aroma-Active Compounds in Northern Highbush Blueberries "Bluecrop" (Vaccinium corymbosum "Bluecrop") and "Elliott" (Vaccinium corymbosum "Elliott") by Gas Chromatography-Olfactometry Dilution Analysis and Odor Activity Value. Journal of Agricultural and Food Chemistry 69 (20), 5691-5701. DOI: 10.1021/acs.jafc.1c01044. 
APPENDIX 1: FIGURES

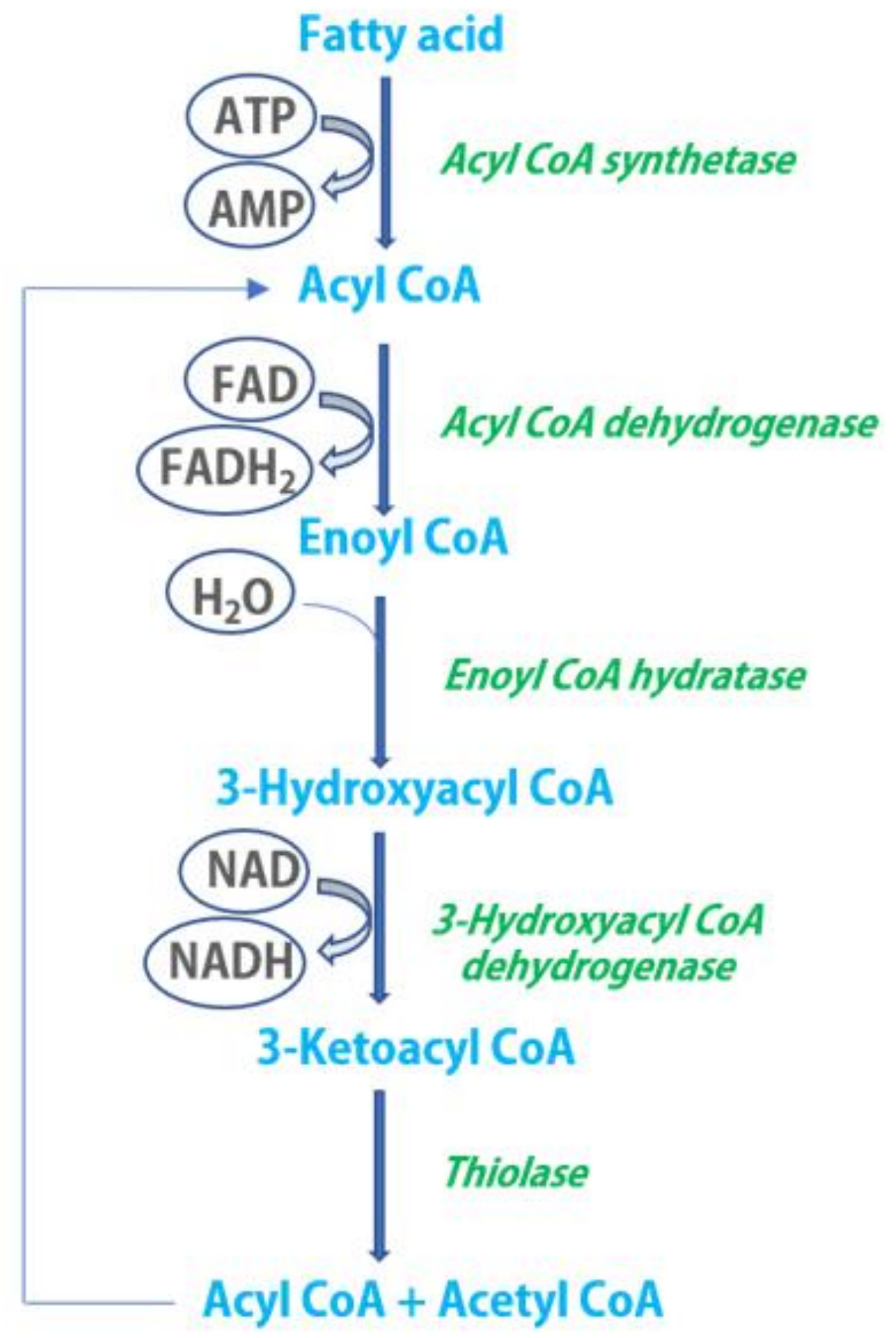

Steps of beta oxidation of fatty acids 


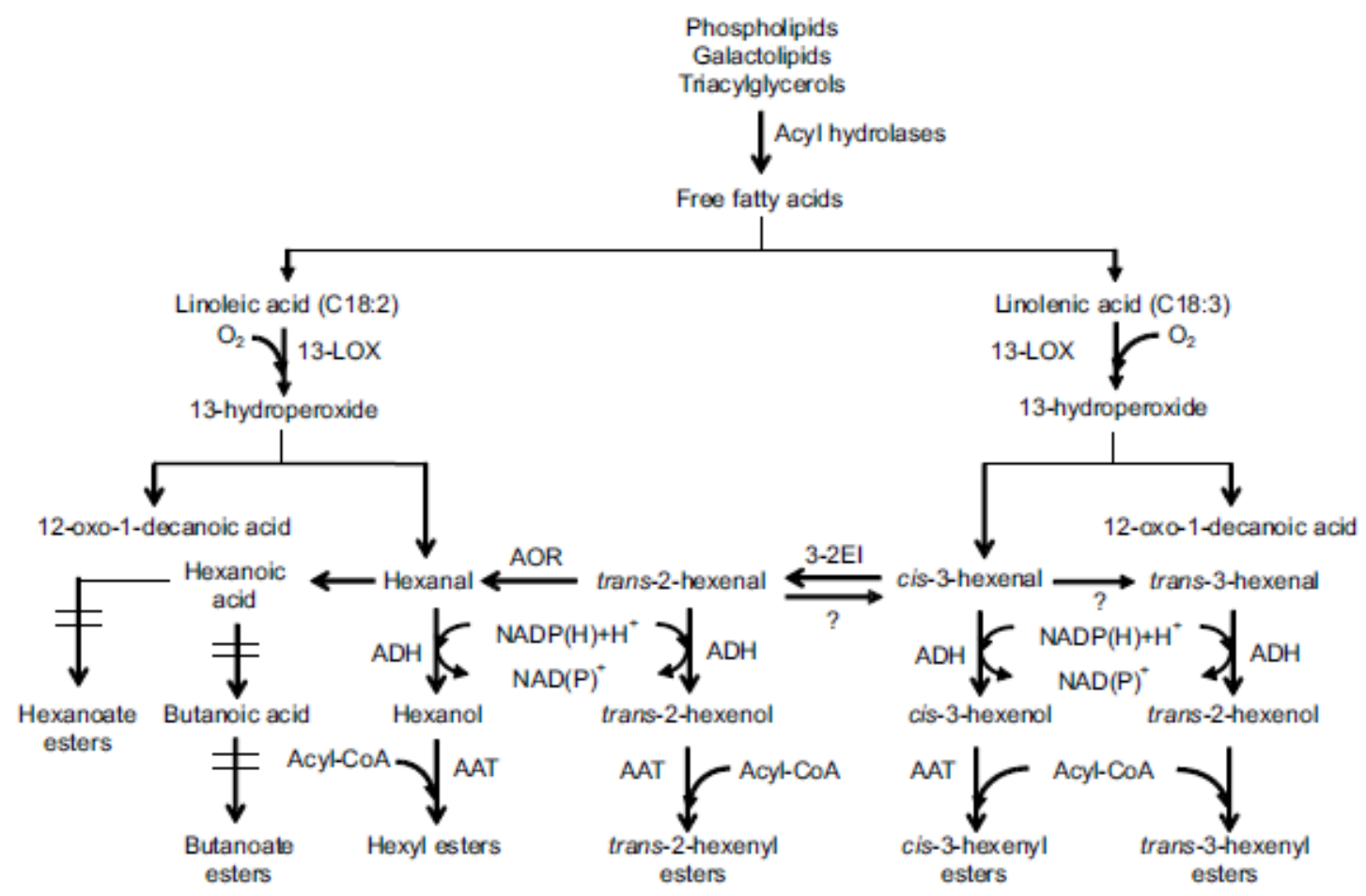

Fig. 2: LOX pathway [5].

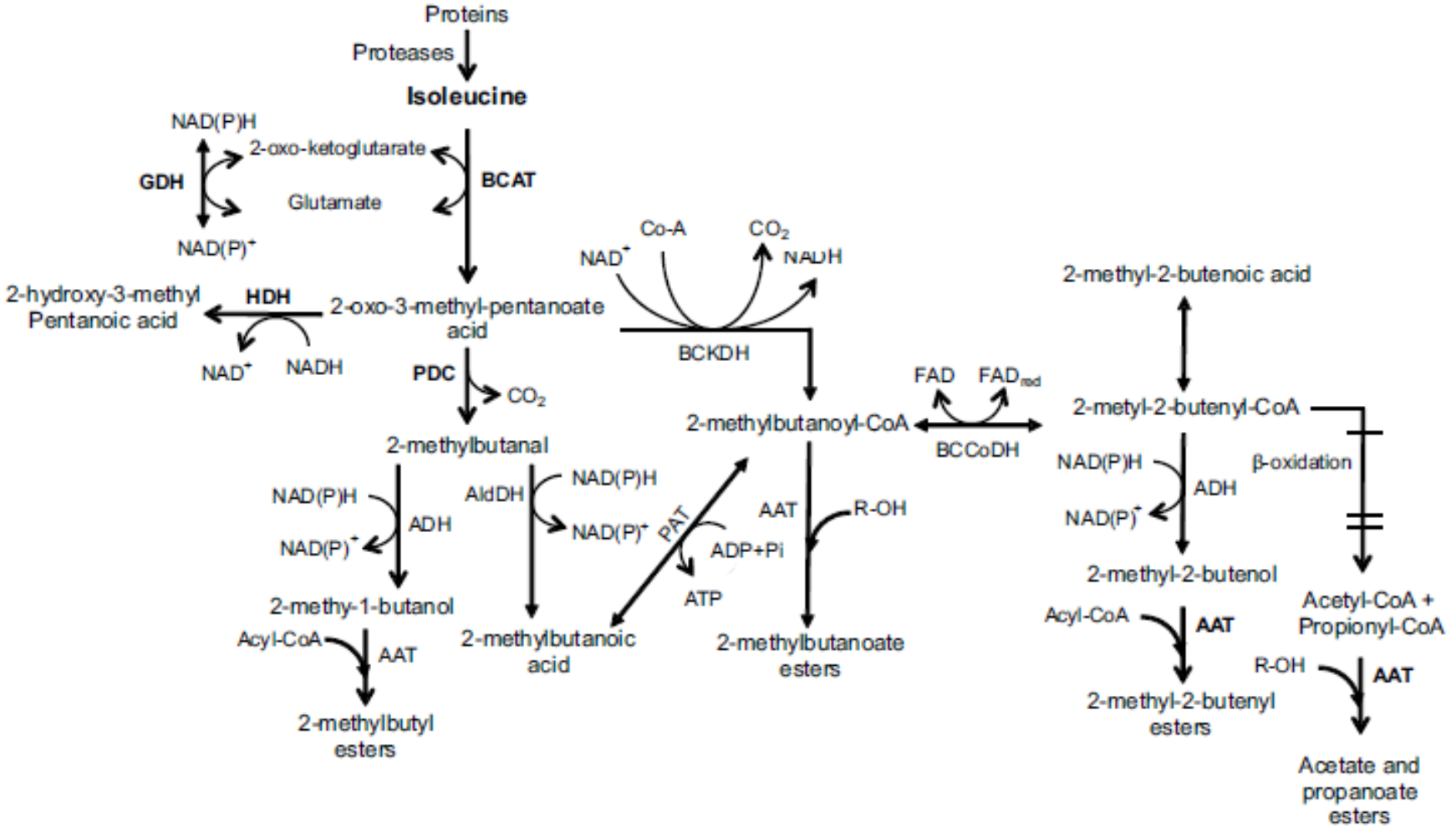


MVA pathway

\section{MEP pathway}

Acetyl-CoA

HMG-COA Mevinolin $\times\lfloor$ HMGR

Mevalonate
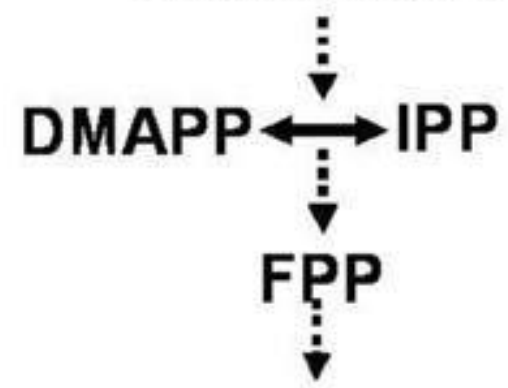

Sesquiterpenes

Triterpenes

Dolichol

Brassinosteroids

Sterols

Cytoplasm

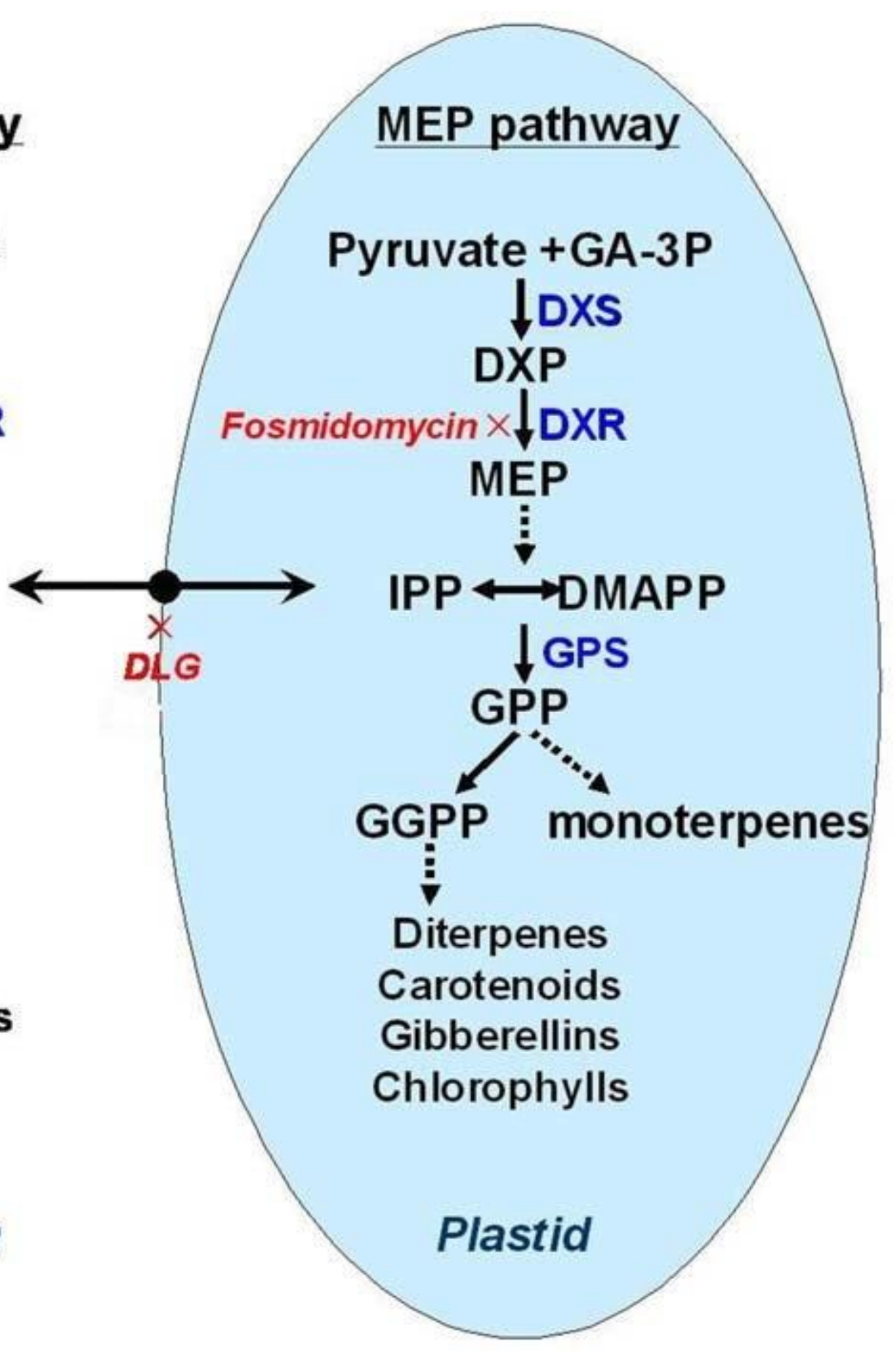




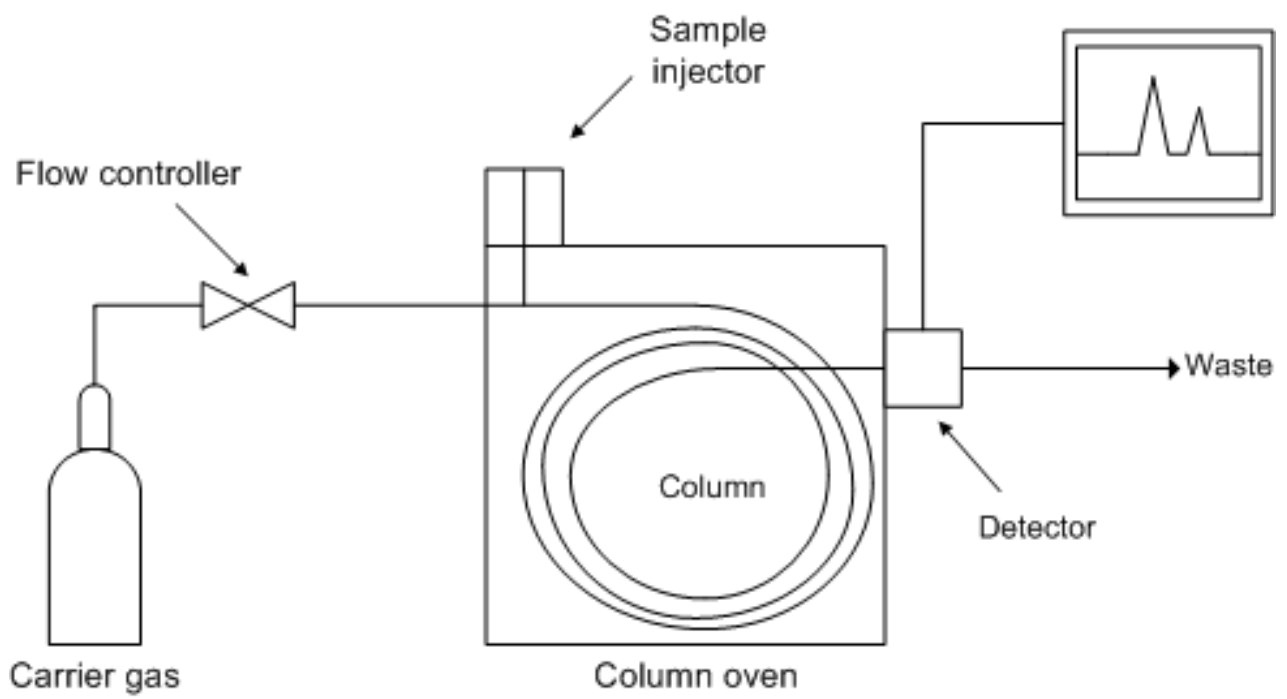

Fig. 5: Schematical illustration of a GC system.

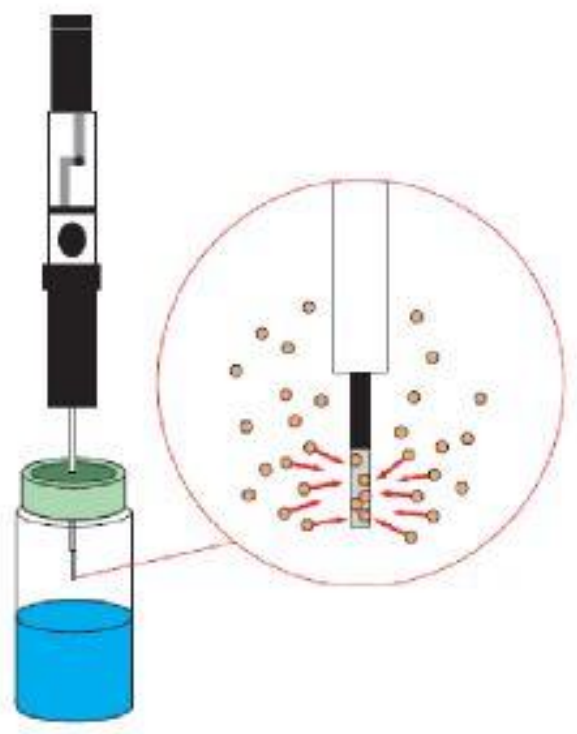

Fig. 6: Illustration of head-space solid-phase micro extraction (HS-SPME) [23]. 

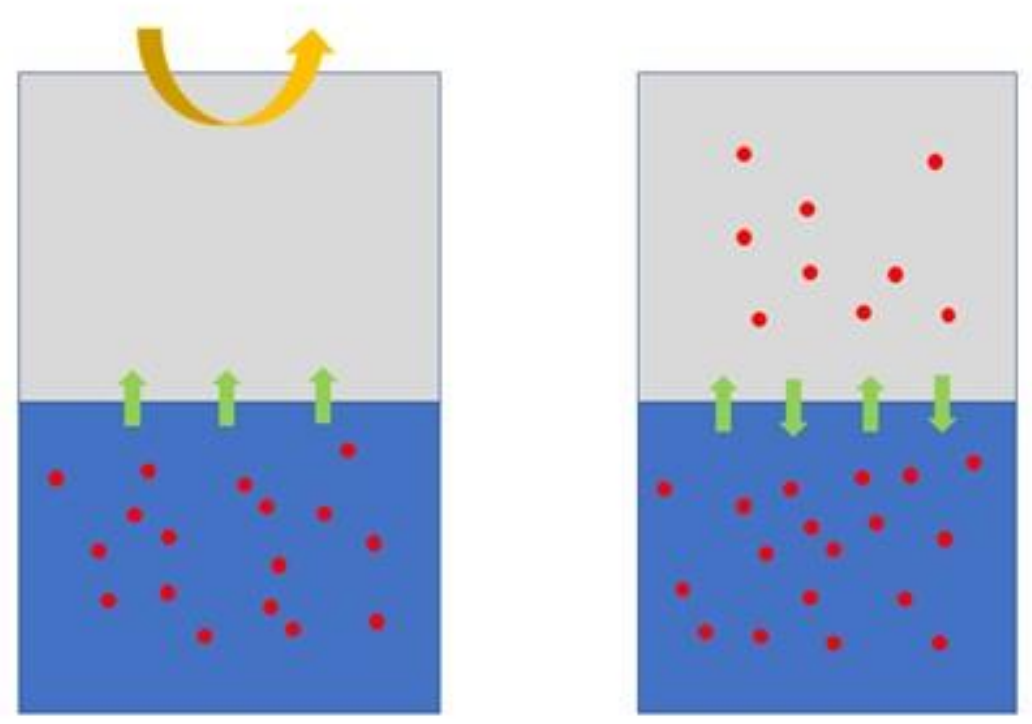

Fig. 7: Dynamic (sx) versus static (dx) headspace.

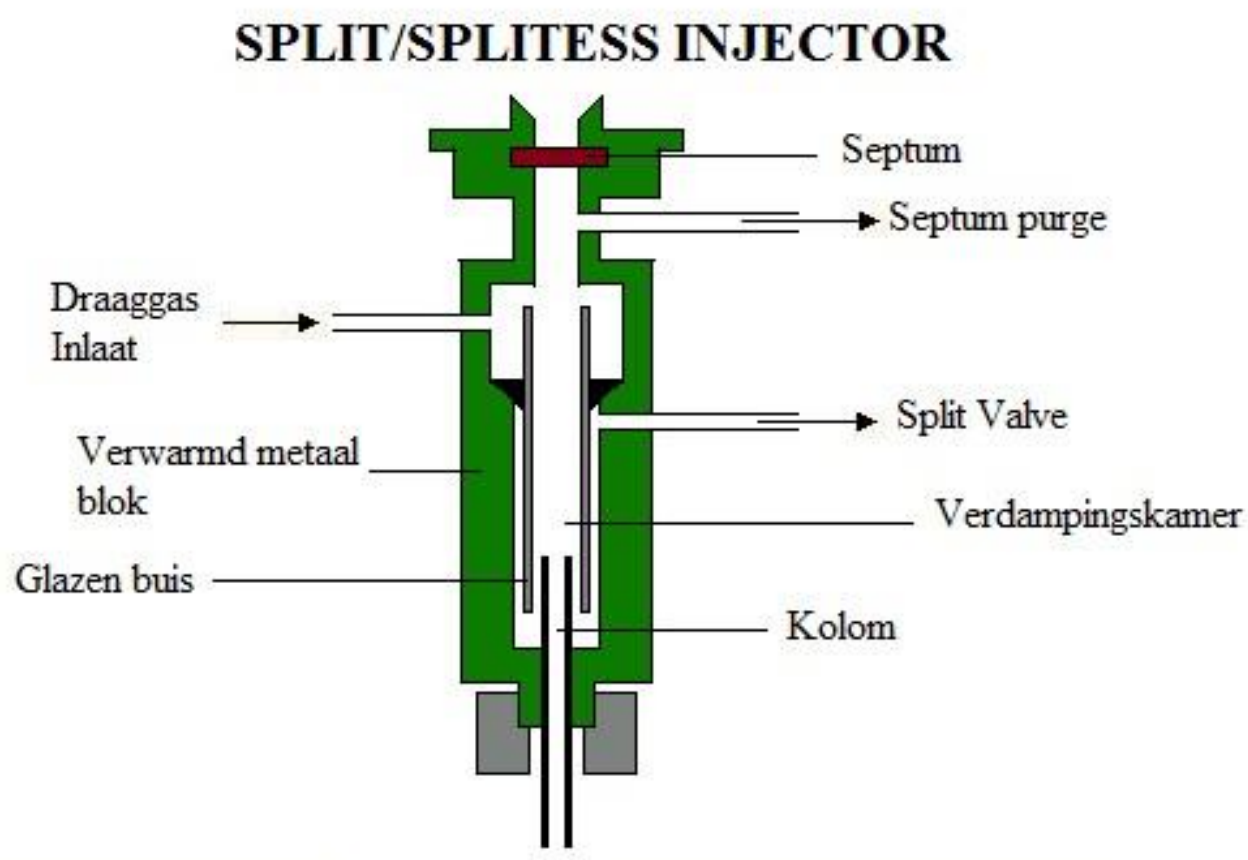

Fig. 8: S/SL injector [29]. 


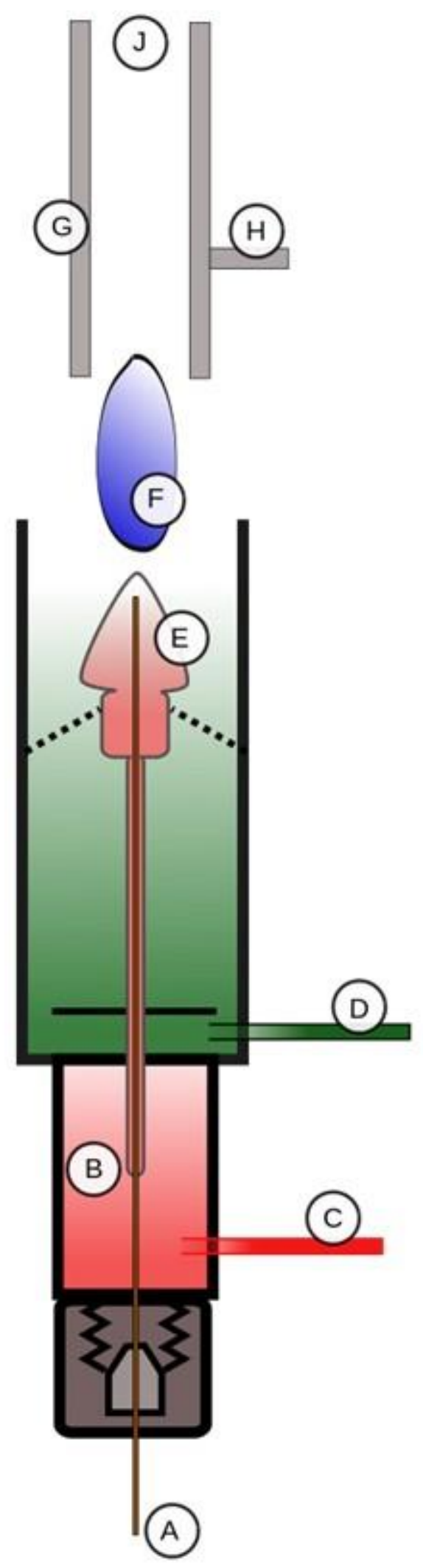

Fig. 9: Schematic illustration of FID. A) Column; B) Platinum jet; C) Hydrogen; D) Air; E) Flame; F) Ions; G) Collector; H) Coaxial cable to analog-todigital converter; J) Gas outlet. 


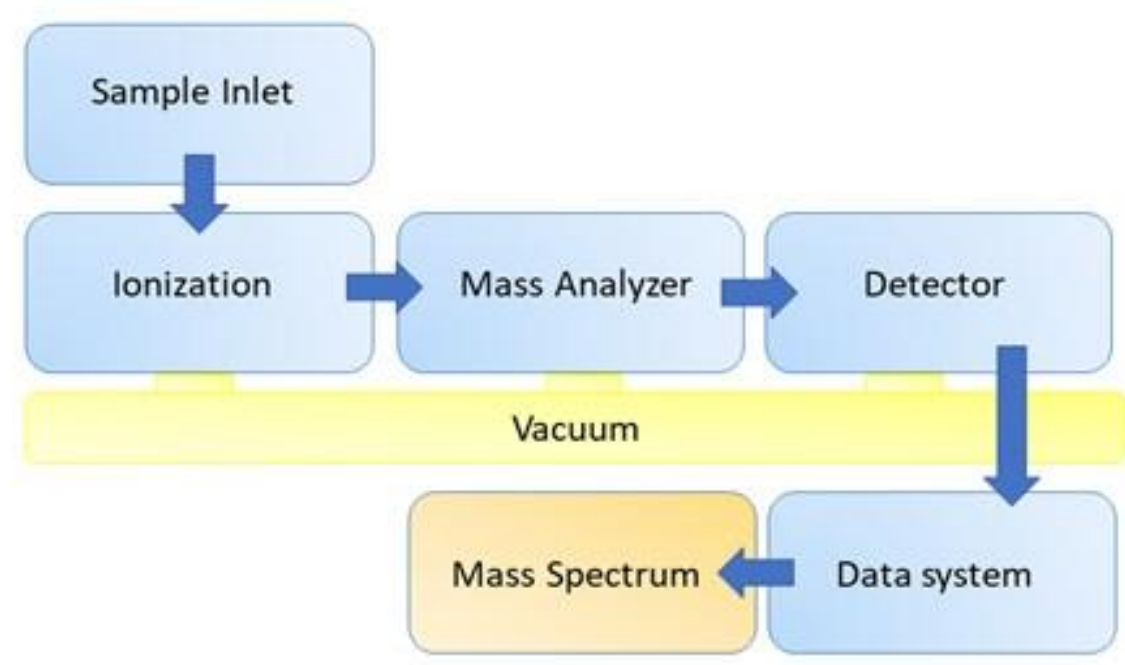

Fig. 10: Schematic illustration of the different parts of a mass spectrometer [12].

of

ions

Fig. 11: Schematic illustration and functional of a Quadrupole (Autor: Angelus, CC BY-SA $3.0<\mathrm{https} / / /$ creativecommons.org/licenses/by-sa/3.0>, via Wikimedia Commons [49]). 


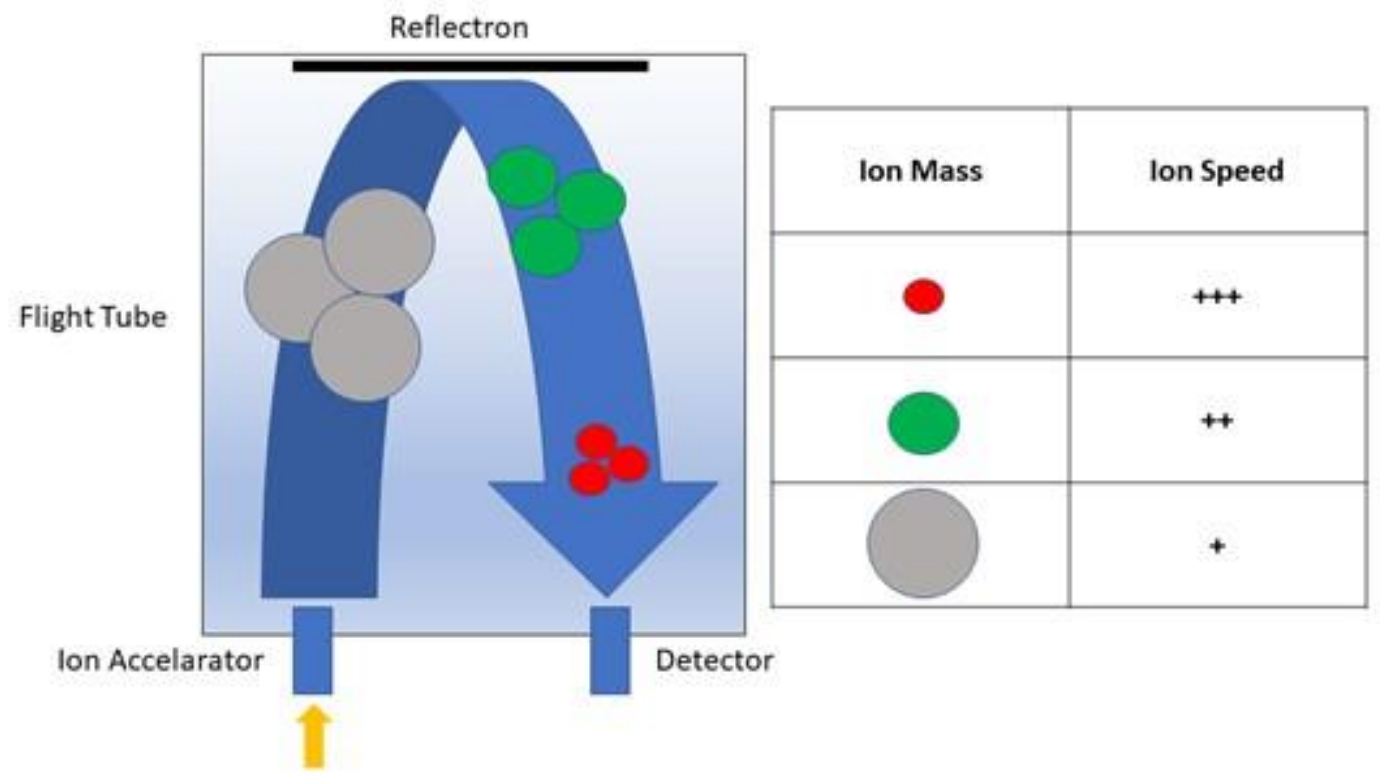

Ion Source

Fig. 12: Illustration of an operating TOF analyzer.

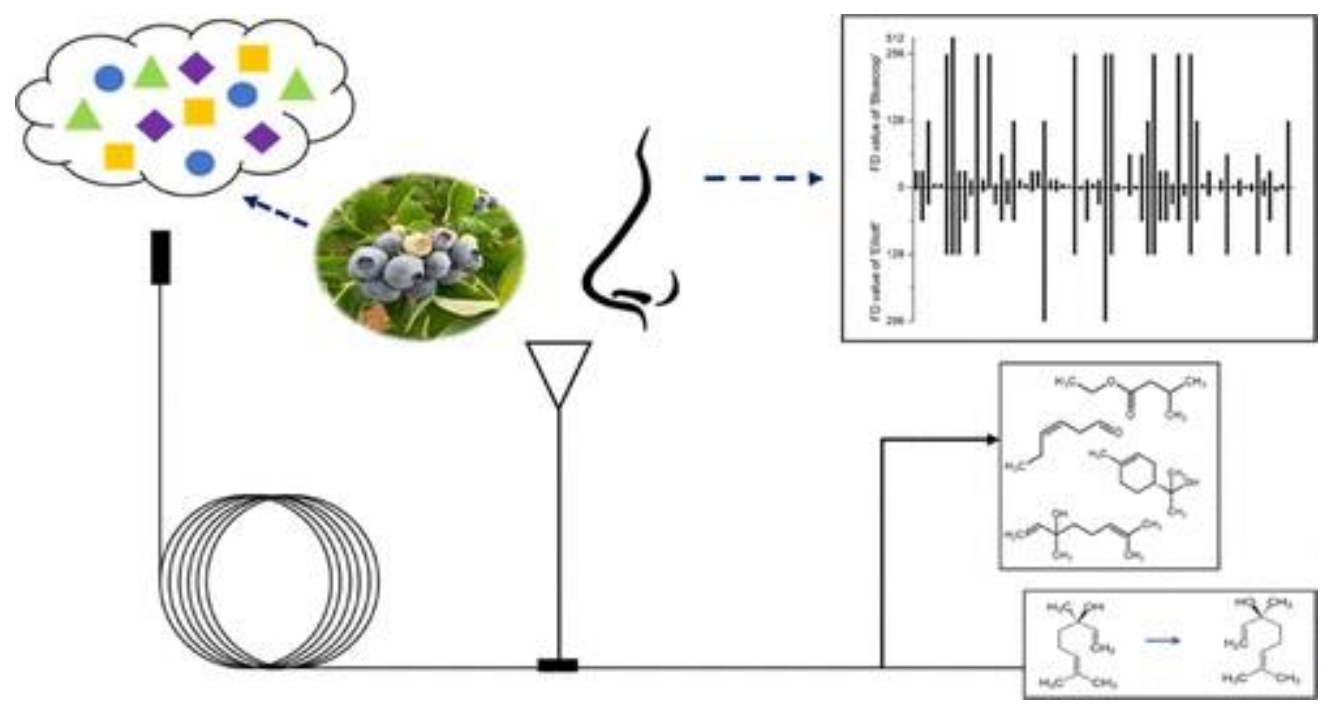

Fig. 13: Illustration of a GC-O/FID (Copyright (2021) American Chemical Society. Reprint with permission. [50]). 


\section{APPENDIX 2: TABLES}

Tab. 1: Sample preparation in GC, pros, and cons.

\begin{tabular}{|c|c|c|}
\hline Technique & Pros & Cons \\
\hline \multirow{4}{*}{ Direct Headspace } & efficient for low-boiling compounds & no traces analysis \\
\hline & readily automated & \\
\hline & no or few interferences & \\
\hline & short analysis time & \\
\hline \multirow{4}{*}{$\begin{array}{l}\text { Headspace -Solid phase } \\
\text { micro-extraction (HS-SPME) }\end{array}$} & no solvent required & fiber saturation \\
\hline & simplicity & competitive adsorption \\
\hline & high precision & \\
\hline & readily automated & \\
\hline \multirow[t]{2}{*}{ Dynamic Headspace } & readily automated & possible contamination \\
\hline & & long analysis time \\
\hline \multirow{3}{*}{ Solvent extraction (LLE) } & quantitative analysis & expensive \\
\hline & liquid injection & possible contamination \\
\hline & & extraction of non-volatile compounds \\
\hline \multirow{4}{*}{ Solid phase extraction (SPE) } & less solvent required & empirical procedures \\
\hline & speed & solvent required \\
\hline & precision and accuracy & \\
\hline & readily automated & \\
\hline $\begin{array}{l}\text { Stir bar sorption extraction } \\
\text { (SBSE) }\end{array}$ & trace analysis & \\
\hline
\end{tabular}


Tab. 2: Sample injection in GC, pros, and cons.

\begin{tabular}{|c|c|c|}
\hline Technique & Pros & Cons \\
\hline \multirow{6}{*}{ Split/splitless, split mode } & high-resolution & no quantitative analysis \\
\hline & no sample dilution & sample in the column not representative of orginal sample \\
\hline & no sample purification & thermal degradation \\
\hline & easily automated & \\
\hline & simplicity & \\
\hline & ruggedness & \\
\hline \multirow{3}{*}{ Split/Splitless, splitless mode } & sensitivity & long analysis time \\
\hline & trace analysis & sample dilution \\
\hline & ruggedness & thermal degradation \\
\hline \multirow{4}{*}{ PTV } & large volume injection & temperature optimization \\
\hline & thermolabile analytes & \\
\hline & split/splitless mode & \\
\hline & flexibility: also liquid injection modes & \\
\hline
\end{tabular}


Tab. 3: Detection, pros, and cons.

\begin{tabular}{|c|c|c|}
\hline Technique & Pros & Cons \\
\hline \multirow{6}{*}{ FID } & high sensitivity & destructive \\
\hline & linearity & low selectivity \\
\hline & simplicity & not possible to couple to other detectors \\
\hline & robustness & \\
\hline & adaptability to columns & \\
\hline & possible to split the flow to use other detectors & \\
\hline \multirow{5}{*}{ Q-MS } & simplicity & destructive \\
\hline & small size & interference of ions \\
\hline & high selectivity & \\
\hline & moderate costs & \\
\hline & rapid scanning & \\
\hline \multirow{5}{*}{ TOF-MS } & large molecules analysis & lower sensitivity \\
\hline & unlimited $\mathrm{m} / \mathrm{z}$ range & low linear dynamic range \\
\hline & sensitivity & destructive \\
\hline & high acquisition rate & \\
\hline & accurate mass measurement & \\
\hline \multirow{3}{*}{ QqQ-MS } & very high selectivity & low resolution \\
\hline & targeted analysis & destructive \\
\hline & trace analysis & \\
\hline \multirow{3}{*}{ Q-TOF-MS } & high resolution & destructive \\
\hline & high sensitivity & \\
\hline & quantitative analysis & \\
\hline \multirow{4}{*}{ Olfactometry } & odour activity relevation & human limitations \\
\hline & used in parallel with other techniques & co-elution of different compounds \\
\hline & quantitative evaluation of the odour & not reliable results \\
\hline & non-destructive & \\
\hline \multirow{5}{*}{ E-nose } & non-destructive & co-elution of different compounds \\
\hline & avoid human limitations & \\
\hline & unknown odours identification & \\
\hline & sensitivity & \\
\hline & used in parallel with other techniques & \\
\hline
\end{tabular}

\section{(c) (i) (\$)}

Dieses Werk ist lizenziert unter einer Creative Commons Namensnennung-Nicht kommerziell 4.0 International Lizenz.

Quest'opera è distribuita con Licenza Creative Commons Attribuzione - Non commerciale 4.0 Internazionale.

This work is licensed under a Creative Commons Attribution-NonCommercial 4.0 International License.

Für alle Abbildungen und Tabellen ohne Nennung des Urhebers gilt: @ Versuchszentrum Laimburg.

Per tutte le immagini e tabelle senza menzione dell'artefice vale: (c) Centro di Sperimentazione Laimburg.

For all figures and tables without mention of the originator applies: (c) Laimburg Research Centre. 